\title{
Anti-inflammatory actions of (-)-epicatechin in the adipose tissue of obese mice
}

${ }^{\star}$ Ahmed Bettaieb ${ }^{a \dagger}$, *Eleonora Cremonini ${ }^{b, c}$, Heeteak Kang ${ }^{b, c}$, Jiye Kang ${ }^{b, c}$, Fawaz G. Haj, ${ }^{\text {b,d }}$, and Patricia I. Oteiza ${ }^{\mathrm{b}, \mathrm{c}}$

*Equally contributed to the manuscript

a'Department of Nutrition, University of Tennessee-Knoxville, Knoxville, TN, USA

Departments of ${ }^{b}$ Nutrition, ${ }^{c}$ Environmental Toxicology, and Internal Medicine, University of California, Davis, USA.

Running tittle: (-)-Epicatechin inhibits adipose tissue inflammation

\section{Corresponding author}

Patricia Oteiza, Ph.D.

Departments of Nutrition/Environmental Toxicology

University of California, Davis

One Shields Avenue, Davis, CA 95616

Phone: 530-754-6074

Fax: 530-752-8966

E-mail: poteiza@ucdavis.edu

\section{Abbreviations:}

ATF6, activating transcription factor 6; EC, (-)-epicatechin; ER, endoplasmic reticulum; Ero1, FAD-dependent enzyme ER oxireductin-1 (Ero1); HFD, high fat diet; 4-HNE, 4-hydroxynonenal; IKB, inhibitor of nuclear factor KB; IKK, IKB kinase; IL-6, interleukin 6; (IRE1 1 ), inositol requiring protein 1a; JNK, c-Jun N-terminal kinase; MCP-1, monocyte chemoattractant protein-1; PDI, protein disulfide isomerase; PERK, PKR-like ER-regulated kinase, ROS, reactive oxygen species; T2D, type 2 diabetes; TNFa, tumor necrosis factor alpha; UPR, unfolded protein response; sXBP-1, X-box binding protein 1 spliced isoform 


\section{Abstract}

Obesity and type 2 diabetes (T2D) are major public health concerns. Visceral adipose tissue inflammation is considered a significant contributor to obesity-associated T2D development. We previously showed that the flavan-3-ol (-)-epicatechin (EC) can mitigate insulin resistance in mice fed a high fat diet (HFD). This study investigated the capacity of EC to inhibit visceral adipose tissue inflammation occurring as a consequence of HFD consumption in C57BL/6J mice, and characterized the underlying mechanisms. In association with the development of obesity and insulin resistance, HFD consumption caused inflammation in the visceral adipose tissue as evidenced by activation of the pro-inflammatory transcription factor NF-KB and increased tissue levels of the macrophage marker F4/80, tumor necrosis factor alpha (TNFa), and the chemokine MCP-1. EC supplementation mitigated all these events. In addition, we observed activation of the three branches of the unfolded protein response (UPR), and upregulation of NADPH oxidases NOX4 and NOX2 in visceral fat of mice fed HFD. These can account, at least in part, for the associated oxidative stress and activation of the redox sensitive NF-kB. Notably, EC supplementation mitigated this and the release of proinflammatory proteins from metabolically stressed adipocytes. Attenuation of adipocyte endoplasmic reticulum (ER) and oxidative stress by EC could contribute to decreased inflammation and improved visceral adipose tissue insulin sensitivity. Our results support the concept that consumption of EC-rich foods could mitigate obesity-associated insulin resistance through attenuation of adipose tissue inflammation.

Key words: inflammation, oxidative stress, (-)-epicatechin, endoplasmic reticulum stress, obesity, adipose tissue 


\section{Introduction}

Obesity is one of the major public health concerns worldwide (Friedman, 2009, Spiegelman and Flier, 2001). Obesity can lead to a number of pathologies including insulin resistance and type 2 diabetes (T2D), cardiovascular and renal diseases, and is considered a risk factor for some cancers. A pathophysiological feature of obesity is a state of low grade chronic systemic inflammation, which is central in the development of T2D (Johnson et al., 2012). In the visceral adipose tissue, obesity causes the accumulation of pro-inflammatory cells, and the progression of a type 1 inflammatory response (Wensveen et al., 2015). Although the mechanisms are not completely understood, stressed adipocytes generate signals that cause the recruitment of macrophages, leading to chronic inflammation and contributing to adipose insulin resistance (Johnson et al., 2012).

Given its secretory capacity, metabolic stress in the adipose tissue may result in oxidative stress and accumulation of misfolded proteins in the lumen of the endoplasmic reticulum (ER) leading to organelle dysfunction, particularly mitochondria and the ER. To prevent the accumulation of misfolded proteins, the ER activates a complex system of signals and chaperones known as the unfolded protein response (UPR). When an oversupply of nutrients is available, the protein folding capacity of the ER can be compromised leading to ER stress (Schroder and Kaufman, 2005). ER stress has been linked to the development of obesityinduced insulin resistance and T2D (Ozcan et al., 2004, Lee and Ozcan, 2014). Indeed, parameters of ER stress activation are found in the adipose tissue from obese and insulin resistant individuals (Boden et al., 2008), which improve after weight loss (Gregor et al., 2009). ER and oxidative stress are intertwined processes (Zeeshan et al., 2016) and both are intimately linked to the development and perpetuation of inflammation. In this regard, during protein folding, particularly in the formation of disulfide bonds, a significant amount of reactive oxygen species (ROS) are generated (Zeeshan et al., 2016). ER stress also induces the 
expression of the NADPH oxidase NOX4 (Li et al., 2010), a major enzymatic cell source of the free radical superoxide anion. As part of the UPR, two redox-sensitive and pro-inflammatory signaling cascades are activated: the c-Jun N-terminal kinase (JNK) and the inhibitor of nuclear factor $\mathrm{KB}(\mathrm{IKB})$ kinase IKK, the later an upstream component of the NF-KB pathway. JNK, and IKK/NF-KB are significant contributors to the downregulation of insulin signaling (Aguirre et al., 2000, Hirosumi et al., 2002, Yuan et al., 2001). Thus, inhibition of ER and oxidative stress can contribute to decreased obesity-induced adipose inflammation and may mitigate the associated insulin resistance.

The flavan-3-ol (-)-epicatechin (EC) is present in the human diet been particularly abundant in berries (grapes), cocoa, and tea (Harnly et al., 2006). We previously demonstrated that EC supplementation can protect rats from insulin resistance by high fructose consumption (Bettaieb et al., 2014) and by the consumption of a HFD in mice (Cremonini et al., 2016). In both conditions EC caused a major improvement in adipose tissue insulin sensitivity which was affected by chronic consumption of excess energy (as fructose or fat). In high fructose-fed mice, EC supplementation improved hepatic and adipose tissue oxidative and ER stress. Treatment of 3T3-L1 adipocytes with the tumor necrosis factor alpha (TNFa) leads to the activation of signals (such as NF-KB and c-Jun N-terminal kinase (JNK)) that sustain inflammation, and induce the expression of chemokines, cytokines, and genes involved in insulin resistance (Vazquez-Prieto et al., 2012). EC, at concentrations attainable in vivo considering all metabolites (Ottaviani et al., 2011), causes a dose-dependent inhibition of both NF-kB and JNK (Vazquez-Prieto et al., 2012)..

EC supplementation mitigates systemic and adipose tissue insulin resistance in a mouse model of HFD-induced obesity and insulin resistance (Cremonini et al., 2016). In this study, we investigated whether improved insulin sensitivity caused by EC supplementation could be in part caused by EC capacity to inhibit adipose tissue inflammation, ER and oxidative stresses. This was linked to the in vitro effects of EC and its metabolites on the release of cytokines and 
adipokines in differentiated 3T3-L1 adipocytes exposed to palmitate. EC supplementation inhibits inflammation, ER and oxidative stresses in visceral adipose tissue and exerts direct effects in adipocytes. This can in part explain the capacity of dietary EC and EC-rich foods to improve insulin sensitivity in rodents and humans (Shrime et al., 2011) (Grassi et al., 2008) (Davison et al., 2008) (Davison et al., 2008, Bettaieb et al., 2014, Cremonini et al., 2016).

\section{Materials and methods}

\subsection{Materials}

3T3-L1 cells were obtained from the American Type Culture Collection (Rockville, MA, USA). Cell culture media and reagents were obtained from Invitrogen Life Technologies (Carlsbad, CA, USA). Antibodies for ATF6 (sc-22799), elF2a (sc-13227), F4/80 (sc-25830), IREa (sc20790), MCP-1 (sc-1785), NOX4 (sc-21860), p-elF2a (Ser49) (sc-293100),p-PERK (Thr980) (sc-32577), p47phox (sc-7660), PERK (sc-13073), sXBP1 (sc-7160), TNFa (sc-1351), and $\beta$ tubulin (sc-9104) were from Santa Cruz Biotechnology (Santa Cruz, CA, USA). Antibodies for

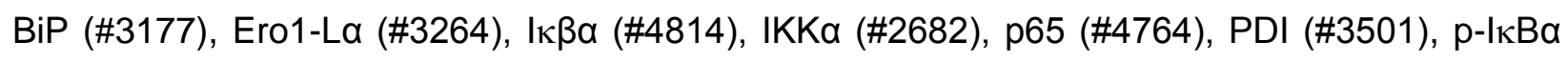
(Ser32) (\#2859), p-IKKa/ß (Ser176/180) (\#2697), and p-p65 (Ser356) (\#3033) were obtained from Cell Signaling Technology (Danvers, MA, USA). 4-Hydroxynonenal (ab46545) and NOX2 (ab29068) antibodies were from Abcam Inc. (Cambridge, MA). Antibody for p-IRE1a (Ser724) (PA1-16927) was from Thermo Fisher Scientific Inc. PVDF membranes were obtained from BIO-RAD (Hercules, CA, USA). The ECL Western blotting system was from Thermo Fisher Scientific Inc. (Piscataway, NJ). EC, palmitate, and all other chemicals were purchased from Sigma-Aldrich Co (St. Louis, MO). The EC metabolite mix was provided by Mars Inc. and contained 25\% EC-3'- $\beta-D$ glucuronide, EC-3'-sulphate, 25\% 3'-O-methylEC-5-sulphate, 5\% 3'- 
O-methylEC-7-sulphate, 5\% 3'-O-methylEC-4'-sulphate, 5\% 4'-O-methylEC-5-sulphate, 5\% 4'O-methylEC-7-sulphate, and 5\% EC-5-sulphate.

\subsection{Animals and animal care}

All procedures were in agreement with standards for care of laboratory animals as outlined in the NIH Guide for the Care and Use of Laboratory Animals. All procedures were administered under the auspices of the Animal Resource Services of the University of California, Davis. Experimental protocols were approved before implementation by the University of California, Davis Animal Use and Care Administrative Advisory Committee.

Healthy male C57BL/6J mice (20-25 g) (8 mice/group) were fed for 15 weeks either: A- a diet containing approximately $10 \%$ total calories from fat (Control) (TD.06416, Harlan Laboratories, Madison, WI), B- a diet containing approximately $60 \%$ total calories from fat (lard) (HFD) (TD.06414, Harlan Laboratories, Madison, WI), or the control $(\mathrm{C}+\mathrm{E})$ and high fat diet $(\mathrm{HFD}+\mathrm{E})$ supplemented in the diet with $20 \mathrm{mg}$ EC/kg body weight. EC-containing diets were prepared every two weeks to account for changes in body weight and food intake, and to prevent EC degradation. All diets were stored at $-20^{\circ} \mathrm{C}$ until use. The amount of EC supplemented with the diet was previously found to be effective improving insulin resistance triggered by both high fructose (Bettaieb et al., 2014) and high fat consumption (Cremonini et al., 2016). In terms of regular human consumption (Vogiatzoglou et al., 2015), this EC amount is high but would be easily attainable through an increased consumption of EC-rich foods or through supplementation.

Body weight and food intake were measured weekly throughout the study (information provided in (Cremonini et al., 2016). After 15 weeks on the dietary treatments, mice were 
euthanized by cervical dislocation. Blood was collected from the abdominal aorta into heparinized tubes, and plasma collected after centrifugation at $1,000 \times \mathrm{g}$ for 15 min at $4^{\circ} \mathrm{C}$. Different adipose tissue pads were collected and weighed. Tissues were flash frozen in liquid nitrogen and then stored at $-80^{\circ} \mathrm{C}$ for further analysis.

\subsection{Cell culture and incubations}

3T3-L1 preadipocytes were maintained in DMEM containing $25 \mathrm{mM}$ glucose, $10 \%(\mathrm{v} / \mathrm{v})$ new born calf serum, $50 \mathrm{U} / \mathrm{mlpenicillin,} \mathrm{and} 50 \mu \mathrm{g} / \mathrm{ml}$ streptomycin. To induce cell differentiation, 3T3-L1 pre-adipocytes were grown to confluency in culture medium containing $10 \%(\mathrm{v} / \mathrm{v})$ fetal bovine serum, and then switched to differentiation medium (DIFM) containing $20 \%(\mathrm{v} / \mathrm{v}$ ) fetal bovine serum, $20 \mathrm{nM}$ insulin and $1 \mathrm{nM}$ triiodothyronine for $48 \mathrm{~h}$. Adipocyte differentiation was induced by treating cells for $48 \mathrm{~h}$ in DIFM further supplemented with $0.5 \mu \mathrm{M}$ dexamethasone, $0.5 \mathrm{mM}$ isobutylmethylxanthine, and $0.125 \mathrm{mM}$ indomethacin. After induction, cells were returned to DIFM medium. On day 12 cells were fully differentiated and exhibited massive accumulation of fat droplets. 3T3-L1 adipocytes were incubated in the absence or the presence of $0.5 \mathrm{mM}$ palmitate with or without $\mathrm{EC}(0.1,1 \mu \mathrm{M})$ or $1 \mu \mathrm{M}$ EC metabolites (a mixture containing the EC metabolites found in human plasma after EC ingestion (Ottaviani et al., 2011). After $24 \mathrm{~h}$ incubation, the medium was collected for subsequent biochemical studies.

\subsection{Western blot analysis}

Tissues and cells were lysed as previously described (Bettaieb et al., 2014, Vazquez-Prieto et al., 2012). Aliquots of total homogenates containing 25-40 $\mu \mathrm{g}$ protein were denatured with Laemmli buffer, separated by reducing $7.5-12.5 \%$ polyacrylamide gel electrophoresis, and electroblotted onto PVDF membranes. Membranes were blocked for $1 \mathrm{~h}$ in 
$5 \%(\mathrm{w} / \mathrm{v})$ bovine serum albumin and subsequently incubated in the presence of the corresponding primary antibodies (1:1,000 dilution) overnight at $4^{\circ} \mathrm{C}$. After incubation for $1 \mathrm{~h}$ at room temperature in the presence of secondary antibodies (HRP conjugated) (1:10,000 dilution) the conjugates were visualized using enhanced chemiluminescence (ECL, Amersham Biosciences) and pixel intensities of immuno-reactive bands were quantified using FluorChem 8900 (Alpha Innotech). Data for phosphorylated proteins are presented as phosphorylation level normalized to protein expression.

\subsection{Determination of leptin, adiponectin, MCP-1 and TNFa concentrations}

Cell medium concentrations of adiponectin (Crystal Chem Inc., Downers Grove, IL), interleukin 6 (IL-6) (Sigma chem. Co., St. Louis, MO); TNFa (Boster Biological Technology Co, Pleasanton, CA), and monocyte chemoattractant protein-1 (MCP-1) (R\&D Systems Inc., Cambridge MA) were measured by ELISA following the manufacturer's protocols.

\section{Results}

\subsection{EC treatment has no apparent effects on adipose tissue mass in HFD-fed mice}

The metabolic parameters for this animal study showing changes in body weight and development of insulin resistance were previously published (Cremonini et al., 2016). Briefly, HFD consumption caused high plasma triglycerides, free fatty acids, cholesterol, and glucose concentrations. EC supplementation prevented HFD-mediated increase in plasma triglycerides and free fatty acids, mitigated the hyperglycemia, but did not affect HFD-triggered hypercholesterolemia. Consumption of HFD for $15 \mathrm{w}$ led to obesity in C57BL/6J mice. Body 
weight gain was partially mitigated by dietary supplementation with $20 \mathrm{mg} \mathrm{EC/g}$ diet (Fig.1 A). The weight of the different fat pads was significantly higher (1.5- to 5.5 -fold) in the HFD-fed group compared to controls. The largest weight increase being observed for the visceral fat pad. EC supplementation did not significantly affect the HFD-mediated fat pads weight increase (Fig.1 A,B). However, EC mitigated HFD-associated increased recruitment of macrophages to the adipose tissue, as evidenced by lower levels of the F4/80 protein, a specific marker of macrophages (Fig.1 C). In this regard, HFD consumption led to a 3.5-fold increase of F4/80 compared to controls, while in mice fed the HFD supplemented with EC the increase was only 1.7- fold above control.

\subsection{EC supplementation inhibits HFD-induced NF-KB activation and inflammation}

Inflammation in the visceral adipose tissue after 15 weeks on HFD was evaluated by measuring: i) activation of transcription factor NF-KB, central to the initiation and perpetuation of inflammation; and ii) tissue concentrations of TNFa and MCP-1.

To evaluate NF-KB activation, the phosphorylation of the upstream kinase IKK, the phosphorylation and degradation of the inhibitory peptide $1 \mathrm{kB}$, and the phosphorylation of the p65 subunit were measured by Western blot. High fat feeding caused a 2.5 -fold increase in IKK phosphorylation, an almost 10-fold increase in IKB and p65 phosphorylation, and an $80 \%$ lower protein content of IKB (Fig. 2A). With the exception of IKB degradation, EC either completely (IKK and IKB phosphorylation) or partially (p65 phosphorylation) inhibited $(\mathrm{p}<0.05)$ the activation of NF-KB signaling pathway.

As further evidence of visceral adipose tissue inflammation, a significant increase in the levels of the pro-inflammatory cytokine TNFa (1.6-fold), and of the chemokine MCP-1 (5.7-fold) was observed in HFD-fed mice compared to controls (Fig. 2B). EC supplementation prevented both TNFa and MCP-1 HFD-induced increases in visceral adipose tissue. 


\subsection{EC supplementation attenuates HFD-induced oxidative and ER stress}

To assess oxidative stress in the visceral adipose tissue we measured the expression of NADPH oxidase subunits gp91 ${ }^{\text {phox }}$ (NOX2), NOX 4 and p47, and the 4-hydroxynonenal (4-HNE) protein derivatives. In the HFD group and after 15 weeks on the diet, we observed a 6.2-,5.5-, and 4.9-fold increase in NOX2, NOX4 and p47 protein levels, respectively, compared to controls

(Fig. 3A). EC prevented HFD-induced increase in NOX4 and p47 expression, and caused a partial decrease in NOX2 expression.

4-HNE is a product of lipid oxidation that can covalently bind to membrane lipids, proteins and nucleic acids. 4-HNE-protein adducts can be measured by Western blot and are an accepted parameter of oxidative stress. The main protein-4HNE derivative was observed in visceral adipose tissue of HFD-fed mice having a molecular weight $\sim 60 \mathrm{kDa}$ (Fig. 3B). In the HFD-fed group a 3.4-fold increase in this 4-HNE-protein derivative was observed, which was prevented by EC supplementation.

We next investigated the effects of HFD consumption and EC supplementation on the three branches of the UPR which are controlled by the ER trans-membrane proteins PKR-like

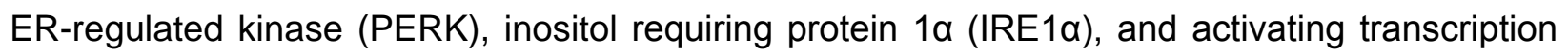
factor 6 (ATF6). HFD consumption triggered ER stress in the visceral fat as assessed by PERK (Thr980) and elF2 $\alpha$ (Ser51) phosphorylation, ATF6 cleavage, JNK and IRE1 $\alpha$ (Ser724) phosphorylation and the levels of X-box binding protein 1 spliced isoform (sXBP-1) (Fig. 4A). EC supplementation partially or completely mitigated HFD-mediated activation of PERK and IRE1a branches, but had no significant effects on ATF6 cleavage. In the HFD-fed group, levels of the BiP/Grp78 chaperone were elevated, and this increase was partially prevented by EC (Fig. 4B). On the other hand, the increased expression in HFD-fed mice visceral fat of two central proteins (FAD-dependent enzyme ER oxireductin-1 (Ero1) and protein disulfide 
isomerase (PDI)) in the formation of disulfide bonds during protein folding was not prevented by EC (Fig. 4B).

3.4. EC mitigates the altered pattern of adipokines secretion caused by palmitate in differentiated 3T3-L1 adipocytes

Exposure of 3T3-L1 differentiated adipocytes to palmitate causes cell triglyceride accumulation and altered patterns of adipokines release (Yeop Han et al., 2010). We observed that incubation of 3T3-L1 adipocytes for $24 \mathrm{~h}$ with $0.5 \mathrm{mM}$ palmitate caused a significant decrease in adiponectin secretion, and an increased secretion of cytokines (IL-6, TNFa) and chemokines (MCP-1) (Fig. 5). At $1 \mu \mathrm{M}$ concentration, EC metabolites (ECM) inhibited palmitate-induced increase in IL-6 and TNFa secretion and decrease in adiponectin secretion. In addition, at 0.1 and $1 \mu \mathrm{M}$ EC prevented palmitate-induced adiponectin decreased release, while $1 \mu \mathrm{M}$ EC mitigated palmitate-induced increase in IL-6 and MCP-1.

\section{Discussion}

This study presents evidence that EC supplementation mitigates visceral adipose tissue inflammation associated with high fat consumption in mice. This is in part due to the capacity of EC to attenuate HFD-induced ER and oxidative stress, and the release of chemokines and cytokines from adipocytes. These observations likely contribute to the capacity of EC to mitigate adipose and systemic insulin resistance associated with HFD-induced obesity (Cremonini et al., 2016).

Both adipocytes and macrophages are central players in obesity-associated visceral adipose tissue inflammation which ultimately contributes to chronic low grade inflammatory state that characterizes obesity (Johnson et al., 2012). In this study, we observed that EC improved several parameters of visceral fat inflammation in HFD-fed mice. Among them, EC mitigated 
adipose macrophage infiltration (lower F4/80 and NOX2 protein levels), the activation of proinflammatory signals (NF-kB), and tissue levels of cytokines (TNFa) and chemokines (MCP-1). A direct effects of EC on adipocytes could be important in the prevention of visceral adipose tissue inflammation (Johnson et al., 2012). Indeed, adipocytes play a major role in macrophage recruitment and activation. Stressed adipocytes secrete pro-inflammatory cytokines and chemokines, and express markers that are sensed by local immune cells resulting in a shift from an anti-inflammatory profile to an M1 macrophage pro-inflammatory polarization (Wensveen et al., 2015). In differentiated adipocytes the exposure to palmitate leads to an increased oxidant production, NF-KB activation, and expression of chemoattractants (MCP-1, serum amyloid A3) (Yeop Han et al., 2010) and different cytokines (Shihabudeen et al., 2015). Supporting a direct action of EC on adipocytes, both EC and its metabolites mitigated palmitate-induced release of cytokines (II-6, TNFa) and chemokines (MCP-1). Significantly, this occurred at EC/EC metabolites concentrations attainable in human plasma/tissues after dietary consumption (Ottaviani et al., 2011, Mullen et al., 2009, Baba et al., 2000, Holt et al., 2002, Actis-Goretta et al., 2012). Of major physiological relevance, EC metabolites, which constitute the majority of human plasma EC such as as glucuronidated, sulphated, and methylated derivatives (ActisGoretta et al., 2012, Ottaviani et al., 2011, Ottaviani et al., 2016), were also effective in those actions.

Adipocyte ER stress contributes to the inflammatory response. ER stress leads to activation of the pro-inflammatory signals JNK and NF-KB (Kitamura, 2009) and promotes the activation of the inflammasome via ROS in mature adipocytes (Kim et al., 2014). In addition, the transcriptional regulator $\mathrm{TRIP}-\mathrm{Br} 2$ has been recently shown to be activated by $\mathrm{ER}$ stress in adipocytes, affecting the expression of inflammatory cytokines and adipokines and acute phase response proteins (Qiang et al., 2016). Here, we demonstrate that HFD consumption leads to ER stress in mouse visceral adipose tissue as evidenced by activation of the three branches of the UPR. This is similar to our previous findings in the adipose tissue from high fructose-fed rats 
(Bettaieb et al., 2014). Of note EC supplementation mitigated the activation of the IRE1 $\alpha$ and PERK branches, but not the ATF6 branch. Attenuation of the IRE1a branch components JNK and IKK by EC (Cremonini et al., 2016) can in part explain the capacity of EC to mitigate adipose tissue inflammation in the HFD-fed mice. However, the fact that EC partially decreases BiP expression while only inhibits two of the three branches of the UPR warrant further investigation.

Oxidative stress at the systemic or adipose level has been observed in obese and overweight individuals (Vincent et al., 2007, Xu et al., 2015). Here we observed increased levels of 4-HNE-protein derivatives, an indicator of oxidative stress, in the HFD mice visceral fat which was prevented by EC supplementation. ER and oxidative stresses are interrelated events (Zeeshan et al., 2016, Santos et al., 2009, Merksamer et al., 2008). Oxidative stress can under certain conditions cause ER stress. On the other hand, ER stress leads to increased ROS production, among others, during protein disulfide bond formation, as a consequence of changes in calcium flux, and via the activation of the NADPH oxidase NOX4 and NADPH-P450 reductase (Zeeshan et al., 2016). PDI is central for disulfide bond formation in the ER during protein folding, where two electrons are transferred to the enzyme. PDI is subsequently oxidized by Ero1 (Tu and Weissman, 2004). Visceral adipose tissue levels of Ero1-La and PDI were elevated in mice fed HFD However, EC supplementation did not prevent their increase suggesting that ROS originated from protein disulfide bond formation during protein folding may not explain the attenuation HFD-induced oxidative stress by EC. On the other hand, we observed that HFD consumption increased the expression of NOX2, NOX4 and p47 in adipose tissue, which was prevented by EC. These findings are similar to what we previously observed in visceral adipose tissue from rats fed high fructose diets (Bettaieb et al., 2014). NADPH oxidase is central to inflammation and its deficiency is linked to lower macrophage infiltration and inflammation in the visceral adipose tissue (Pepping et al., 2013). NOX2 is the NADPH oxidase mainly present in phagocytic cells and required for activation the assembly of a six units 
complex which includes gp9 $1^{\text {phox }}$ and $\mathrm{p} 47$. In the visceral adipose tissue from HFD fed mice, the increase in the NOX2 subunits gp9 $1^{\text {phox }}$ and p47 could be primarily due to an increased macrophage infiltration occurring secondary to obesity. ER stress-associated NOX4 activation can occur not only through an increase in NOX4 expression (Pedruzzi et al., 2004) but through modulation of its activity via NOX4 recruitment to lipid rafts (Han et al., 2012). Importantly, not only EC can act through the observed inhibition of HFD-mediated NOX4 overexpression but also through a direct inhibition of the enzyme activity (Steffen et al., 2008, Steffen et al., 2007). EC-mediated inhibition of NADPH oxidases, would have a significant inhibitory impact on adipose inflammation in obese mice. Additionally, It is important to consider that HFD consumption can also lead to an increased reactive oxygen and nitrogen species production from other cellular sources, including mitochondria (Paglialunga et al., 2015), the activation of nitric oxide (NO) synthase (Tsuchiya et al., 2007) and myeloperoxidase (Wang et al., 2014). In this regard, higher levels of lipid-supported hydrogen peroxide release from mitochondria were observed both in epididymal and inguinal fat from mice fed HFD compared to controls (Paglialunga et al., 2015). In terms of NO synthase, EC-mediated increase in NO production has beneficial effects on vascular alterations associated with high fat/high fructose consumption (Ramirez-Sanchez et al., 2016, Litterio et al., 2012). On the other hand, high tissue NO contributes to adipose inflammation (Tsuchiya et al., 2007) which can be in part due to the formation of the strong oxidant peroxynitrite. Although in the current work we have not studied these oxidant sources, they can contribute to obesity-associated adipose inflammation and could also be potential EC targets.

Induction of ER stress in adipocytes with tunicamycin or thapsigargin leads to a decrease in adiponectin expression (Mondal et al., 2012). Adiponectin is synthesized and released by adipocytes and modulates glucose homeostasis but also has anti-inflammatory actions (Barnes et al., 2015). In this regard, adiponectin promotes the expression of anti-inflammatory molecules, inhibits NF-KB and the associated production of pro-inflammatory cytokines, and 
inhibits phagocytic activity (Barnes et al., 2015). EC improved adiponectin production and release in 3T3-L3 adipocytes treated with TNFa (Vazquez-Prieto et al., 2012). Accordingly, we observed that EC and its metabolites also have the capacity to restore adiponectin secretion in palmitate-stressed adipocytes. Thus, this mechanism could also contribute to the antiinflammatory actions of EC in the HFD-fed obese mice. Very importantly, the concentration of EC and its metabolites that were effective restoring adiponectin secretion are consistent with those found in human plasma after EC consumption (Ottaviani et al., 2011).

\section{Conclusions}

In summary (Fig. 6), consumption of a high fat diet leads to fat accumulation and adipocyte hypertrophy. The associated increased protein synthesis surpasses the capacity of the ER to control the normal protein folding, and the UPR response is activated, ER stress contributes to oxidative stress, in part via NOX4 increased expression, and leads to the upregulation of redoxsensitive signals (JNK, IKK/NF-KB) which promote the expression and release of cytokines/chemokines. This contributes to the recruitment of macrophages, change of M2 to M1 immune response that ultimately leads to the secretion of cytokines by macrophages, continuing a cycle of adipose tissue inflammation. We propose that EC could exert anti-inflammatory actions in adipose tissue by: 1- attenuating ER stress through mechanisms not yet elucidated; 2inhibiting NADPH oxidase expression/activity and the associated oxidative stress; 3-inhibiting NF-KB activation through redox-dependent and independent (direct interaction) mechanisms, and 4-improving the altered pattern of anti- and pro-inflammatory molecules secreted by metabolically-stressed adipocytes. Thus, our data suggest that EC may contribute to improved insulin sensitivity in overweight/obese individual in part through mitigation of systemic and adipose tissue inflammation. 


\section{Acknowledgements}

This work was supported by the NIFA-USDA (CA-D*-xxx-7244-H). A.B is funded by NIH/NIDDK [R00DK100736]. Research in the F.G.H laboratory is funded by NIH grants R01DK090492 and R01DK095359. We thank Mars Inc. for kindly providing the EC metabolites. PIO is a honorary researcher from CONICET, Argentina. 


\section{Legend to figures}

Figure 1. Effects of EC supplementation on adiposity and visceral adipose tissue macrophage infiltration. A,B- Fat pads in mice fed for 15 weeks a control diet without (C) or with (CE) EC supplementation, or a HFD diet without (HF) or with (HFE) EC supplementation for 15 weeks. C- F4/80 protein levels in visceral adipose tissue were measured by Western blot and normalized to $\beta$-tubulin content. Results are shown as mean \pm SEM of $5-8$ animals/treatment. *, are significantly different from controls, and are significantly different among each other. $(p<0.05$, one-way ANOVA test).

Figure 2. Effects of EC supplementation on inflammation in visceral adipose tissue: activation of the pro-inflammatory NF-KB pathway and expression of cytokines and chemokines. A- Different key signaling proteins in the NF-KB pathway were evaluated in mouse visceral adipose tissue after 15 weeks on the corresponding diets (see legend to Fig.1), measuring: A- Phosphorylation of IKKa/ß (Ser178/180), phosphorylation (Ser32) and total levels of IKBa, and phosphorylation of p65 (Ser536); B- TNFa and MCP-1 (NF-kB target genes) protein levels. Bands were quantified and results for the CE, HF and HFE were normalized to control group values (C). Results are shown as mean \pm SEM of 8 animals/treatment. *," are significantly different from controls, and are significantly different among them. $(p<0.05$, oneway ANOVA test).

Figure 3. Effects of EC supplementation on parameters of oxidative stress in visceral adipose tissue: upregulation of NADPH oxidase subunits and lipid oxidation. A: Protein levels of NOX subunits (NOX2 (gp91 ${ }^{\text {phox }}$ ), NOX4, p47) were measured by Western blot. BProtein-4-HNE conjugates (HNE) were measured by Western blot; the main 4-HNE-conjugated 
band with a MW of approximately $60 \mathrm{kDa}$ is shown. Bands were quantified and results for the CE, HF and HFE groups were normalized to control group values (C). Results are shown as mean \pm SEM of 8 animals/treatment. * ${ }^{*}$ \# are significantly different from control groups and are significantly different among them; • significantly different from all other groups. $(p<0.05$, oneway ANOVA test).

Figure 4. Effects of EC supplementation on parameters of ER stress in visceral adipose tissue. The three branches of the UPR response were evaluated by Western blot measuring: A-PERK (Thr980), elF2a (Ser51), and IRE1a (Ser724) phosphorylation, sXBP-1 and cleaved ATF6 (cATF6); and B- BiP, Ero1-La and PDI. Bands were quantified and results for for the CE, HF and HFE groups were normalized to control group values (C). Phosphorylated/total ratios were calculated for PERK, elFa and IRE1 $\alpha$. sXBP-1, CATF6, BiP, Ero1-La and PDI were normalized to $\beta$-tubulin (tub) content. Results are shown as mean \pm SEM of 6 animals/treatment. * \# are significantly different from all other groups and among them. $(p<0.05$, one-way ANOVA test).

Figure 5. EC mitigates the altered pattern of adipokines secretion caused by palmitate in differentiated 3T3-L1 adipocytes. 3T3-L1 adipocytes were incubated without or with EC (0.1, $1 \mu \mathrm{M})$ or $\mathrm{EC}$ metabolites $(\mathrm{ECM})(1 \mu \mathrm{M})$ and in the absence or presence of $0.5 \mathrm{mg} / \mathrm{ml}$ palmitate for 24 h. A- Adiponectin, B-IL-6, C-MCP-1, and D-TNFa concentrations were measured by ELISA in the cell culture medium. Results are shown as mean \pm SEM of 3 independent experiments. Values having different superscripts are significantly different $(p<0.05$, one way ANOVA test). 
Figure 6. Proposed mechanisms of EC anti-inflammatory actions in adipose tissue of HFD-fed mice. A scheme depicting potential mechanisms via which anti-inflammatory effects are exerted by (-)-epicatechin in the adipose tissue. 


\section{References}

National Cholesterol Education Program National Heart, Lung, and Blood Institute. Third Report of the National Cholesterol Education Program (NECP) Expert Panel on Detection, Evaluation and Treatments of High Blood Cholesterol in Adults (Adult Treatments Panel III) Executive Summary, National Institutes of Health NIH Publication No. 01-3670, May 2001.

Actis-Goretta, L., Leveques, A., Giuffrida, F., Romanov-Michailidis, F., Viton, F., Barron, D., Duenas-Paton, M., Gonzalez-Manzano, S., Santos-Buelga, C., Williamson, G. \& Dionisi, F. (2012). Elucidation of (-)-epicatechin metabolites after ingestion of chocolate by healthy humans. Free Radic Biol Med, 53, 787-795.

Aguirre, V., Uchida, T., Yenush, L., Davis, R. \& White, M. F. (2000). The c-Jun NH(2)-terminal kinase promotes insulin resistance during association with insulin receptor substrate-1 and phosphorylation of Ser(307). J Biol Chem, 275, 9047-9054.

Baba, S., Osakabe, N., Yasuda, A., Natsume, M., Takizawa, T., Nakamura, T. \& Terao, J. (2000). Bioavailability of (-)-epicatechin upon intake of chocolate and cocoa in human volunteers. Free Radic Res, 33, 635-641.

Barnes, M. A., Carson, M. J. \& Nair, M. G. (2015). Non-traditional cytokines: How catecholamines and adipokines influence macrophages in immunity, metabolism and the central nervous system. Cytokine, 72, 210-219.

Bettaieb, A., Vazquez-Prieto, M. A., Lanzi, C. R., Miatello, R. M., Haj, F. G., Fraga, C. G. \& Oteiza, P. I. (2014). (-)-Epicatechin mitigates high fructose-associated insulin resistance by modulating redox signaling and endoplasmic reticulum stress. Free Radic Biol Med. 
Boden, G., Duan, X., Homko, C., Molina, E. J., Song, W., Perez, O., Cheung, P. \& Merali, S. (2008). Increase in endoplasmic reticulum stress-related proteins and genes in adipose tissue of obese, insulin-resistant individuals. Diabetes, 57, 2438-2444.

Cremonini, E., Bettaieb, A., Haj, F. G., Fraga, C. G. \& Oteiza, P. I. (2016). (-)-Epicatechin improves insulin sensitivity in high fat diet-fed mice. Arch Biochem Biophys, 599, 13-21.

Davison, K., Coates, A. M., Buckley, J. D. \& Howe, P. R. (2008). Effect of cocoa flavanols and exercise on cardiometabolic risk factors in overweight and obese subjects. Int J Obes (Lond), $32,1289-1296$.

Friedman, J. M. (2009). Obesity: Causes and control of excess body fat. Nature, 459, 340-342.

Grassi, D., Desideri, G., Necozione, S., Lippi, C., Casale, R., Properzi, G., Blumberg, J. B. \& Ferri, C. (2008). Blood pressure is reduced and insulin sensitivity increased in glucoseintolerant, hypertensive subjects after 15 days of consuming high-polyphenol dark chocolate. J Nutr, 138, 1671-1676.

Gregor, M. F., Yang, L., Fabbrini, E., Mohammed, B. S., Eagon, J. C., Hotamisligil, G. S. \& Klein, S. (2009). Endoplasmic reticulum stress is reduced in tissues of obese subjects after weight loss. Diabetes, 58, 693-700.

Han, C. Y., Umemoto, T., Omer, M., Den Hartigh, L. J., Chiba, T., LeBoeuf, R., Buller, C. L., Sweet, I. R., Pennathur, S., Abel, E. D. \& Chait, A. (2012). NADPH oxidase-derived reactive oxygen species increases expression of monocyte chemotactic factor genes in cultured adipocytes. J Biol Chem, 287, 10379-10393.

Harnly, J. M., Doherty, R. F., Beecher, G. R., Holden, J. M., Haytowitz, D. B., Bhagwat, S. \& Gebhardt, S. (2006). Flavonoid content of U.S. fruits, vegetables, and nuts. J Agric Food Chem, $54,9966-9977$. 
Hirosumi, J., Tuncman, G., Chang, L., Gorgun, C. Z., Uysal, K. T., Maeda, K., Karin, M. \& Hotamisligil, G. S. (2002). A central role for JNK in obesity and insulin resistance. Nature, 420, 333-336.

Holt, R. R., Lazarus, S. A., Sullards, M. C., Zhu, Q. Y., Schramm, D. D., Hammerstone, J. F., Fraga, C. G., Schmitz, H. H. \& Keen, C. L. (2002). Procyanidin dimer B2 [epicatechin-(4beta-8)epicatechin] in human plasma after the consumption of a flavanol-rich cocoa. 76, 4.

Johnson, A. R., Milner, J. J. \& Makowski, L. (2012). The inflammation highway: metabolism accelerates inflammatory traffic in obesity. Immunol Rev, 249, 218-238.

Kim, S., Joe, Y., Jeong, S. O., Zheng, M., Back, S. H., Park, S. W., Ryter, S. W. \& Chung, H. T. (2014). Endoplasmic reticulum stress is sufficient for the induction of IL-1beta production via activation of the NF-kappaB and inflammasome pathways. Innate Immun, 20, 799-815.

Kitamura, M. (2009). Biphasic, bidirectional regulation of NF-kappaB by endoplasmic reticulum stress. Antioxid Redox Signal, 11, 2353-2364.

Lee, J. \& Ozcan, U. (2014). Unfolded protein response signaling and metabolic diseases. J Biol Chem, 289, 1203-1211.

Li, G., Scull, C., Ozcan, L. \& Tabas, I. (2010). NADPH oxidase links endoplasmic reticulum stress, oxidative stress, and PKR activation to induce apoptosis. J Cell Biol, 191, 1113-1125.

Litterio, M. C., Jaggers, G., Sagdicoglu Celep, G., Adamo, A. M., Costa, M. A., Oteiza, P. I., Fraga, C. G. \& Galleano, M. (2012). Blood pressure-lowering effect of dietary (-)-epicatechin administration in L-NAME-treated rats is associated with restored nitric oxide levels. Free Radic Biol Med, 53, 1894-1902. 
Merksamer, P. I., Trusina, A. \& Papa, F. R. (2008). Real-time redox measurements during endoplasmic reticulum stress reveal interlinked protein folding functions. Cell, 135, 933-947.

Mondal, A. K., Das, S. K., Varma, V., Nolen, G. T., McGehee, R. E., Elbein, S. C., Wei, J. Y. \& Ranganathan, G. (2012). Effect of endoplasmic reticulum stress on inflammation and adiponectin regulation in human adipocytes. Metab Syndr Relat Disord, 10, 297-306.

Mullen, W., Borges, G., Donovan, J. L., Edwards, C. A., Serafini, M., Lean, M. E. \& Crozier, A. (2009). Milk decreases urinary excretion but not plasma pharmacokinetics of cocoa flavan-3-ol metabolites in humans. Am J Clin Nutr, 89, 1784-1791.

Ottaviani, J. I., Borges, G., Momma, T. Y., Spencer, J. P., Keen, C. L., Crozier, A. \& Schroeter, H. (2016). The metabolome of [2-(14)C](-)-epicatechin in humans: implications for the assessment of efficacy, safety, and mechanisms of action of polyphenolic bioactives. Sci Rep, 6, 29034.

Ottaviani, J. I., Momma, T. Y., Kuhnle, G. K., Keen, C. L. \& Schroeter, H. (2011). Structurally related (-)-epicatechin metabolites in humans: Assessment using de novo chemically synthesized authentic standards. Free Radic Biol Med.

Ozcan, U., Cao, Q., Yilmaz, E., Lee, A. H., Iwakoshi, N. N., Ozdelen, E., Tuncman, G., Gorgun, C., Glimcher, L. H. \& Hotamisligil, G. S. (2004). Endoplasmic reticulum stress links obesity, insulin action, and type 2 diabetes. Science, 306, 457-461.

Paglialunga, S., Ludzki, A., Root-McCaig, J. \& Holloway, G. P. (2015). In adipose tissue, increased mitochondrial emission of reactive oxygen species is important for short-term high-fat diet-induced insulin resistance in mice. Diabetologia, 58, 1071-1080.

Pedruzzi, E., Guichard, C., Olivier, V., Driss, F., Fay, M., Prunet, C., Marie, J. C., Pouzet, C., Samadi, M., Elbim, C., O'Dowd, Y., Bens, M., Vandewalle, A., Gougerot-Pocidalo, M. A., Lizard, 
G. \& Ogier-Denis, E. (2004). NAD(P)H oxidase Nox-4 mediates 7-ketocholesterol-induced endoplasmic reticulum stress and apoptosis in human aortic smooth muscle cells. Mol Cell Biol, 24, 10703-10717.

Pepping, J. K., Freeman, L. R., Gupta, S., Keller, J. N. \& Bruce-Keller, A. J. (2013). NOX2 deficiency attenuates markers of adiposopathy and brain injury induced by high-fat diet. Am J Physiol Endocrinol Metab, 304, E392-404.

Qiang, G., Kong, H. W., Fang, D., McCann, M., Yang, X., Du, G., Bluher, M., Zhu, J. \& Liew, C. W. (2016). The obesity-induced transcriptional regulator TRIP-Br2 mediates visceral fat endoplasmic reticulum stress-induced inflammation. Nat Commun, 7, 11378.

Ramirez-Sanchez, I., Rodriguez, A., Moreno-Ulloa, A., Ceballos, G. \& Villarreal, F. (2016). (-)Epicatechin-induced recovery of mitochondria from simulated diabetes: Potential role of endothelial nitric oxide synthase. Diab Vasc Dis Res, 13, 201-210.

Santos, C. X., Tanaka, L. Y., Wosniak, J. \& Laurindo, F. R. (2009). Mechanisms and implications of reactive oxygen species generation during the unfolded protein response: roles of endoplasmic reticulum oxidoreductases, mitochondrial electron transport, and NADPH oxidase. Antioxid Redox Signal, 11, 2409-2427.

Schroder, M. \& Kaufman, R. J. (2005). The mammalian unfolded protein response. Annu Rev Biochem, 74, 739-789.

Shihabudeen, M. S., Roy, D., James, J. \& Thirumurugan, K. (2015). Chenodeoxycholic acid, an endogenous FXR ligand alters adipokines and reverses insulin resistance. Mol Cell Endocrinol, 414, 19-28. 
Shrime, M. G., Bauer, S. R., McDonald, A. C., Chowdhury, N. H., Coltart, C. E. \& Ding, E. L. (2011). Flavonoid-rich cocoa consumption affects multiple cardiovascular risk factors in a metaanalysis of short-term studies. J Nutr, 141, 1982-1988.

Spiegelman, B. M. \& Flier, J. S. (2001). Obesity and the regulation of energy balance. Cell, 104, $531-543$.

Steffen, Y., Gruber, C., Schewe, T. \& Sies, H. (2008). Mono-O-methylated flavanols and other flavonoids as inhibitors of endothelial NADPH oxidase. Arch Biochem Biophys, 469, 209-219.

Steffen, Y., Schewe, T. \& Sies, H. (2007). (-)-Epicatechin elevates nitric oxide in endothelial cells via inhibition of NADPH oxidase. Biochem Biophys Res Commun, 359, 828-833.

Tsuchiya, K., Sakai, H., Suzuki, N., Iwashima, F., Yoshimoto, T., Shichiri, M. \& Hirata, Y. (2007). Chronic blockade of nitric oxide synthesis reduces adiposity and improves insulin resistance in high fat-induced obese mice. Endocrinology, 148, 4548-4556.

Tu, B. P. \& Weissman, J. S. (2004). Oxidative protein folding in eukaryotes: mechanisms and consequences. J Cell Biol, 164, 341-346.

Vazquez-Prieto, M. A., Bettaieb, A., Haj, F. G., Fraga, C. G. \& Oteiza, P. I. (2012). (-)Epicatechin prevents TNFalpha-induced activation of signaling cascades involved in inflammation and insulin sensitivity in 3T3-L1 adipocytes. Arch Biochem Biophys.

Vincent, H. K., Innes, K. E. \& Vincent, K. R. (2007). Oxidative stress and potential interventions to reduce oxidative stress in overweight and obesity. Diabetes Obes Metab, 9, 813-839.

Vogiatzoglou, A., Mulligan, A. A., Lentjes, M. A., Luben, R. N., Spencer, J. P., Schroeter, H., Khaw, K. T. \& Kuhnle, G. G. (2015). Flavonoid intake in European adults (18 to 64 years). PLoS One, 10, e0128132. 
Wang, Q., Xie, Z., Zhang, W., Zhou, J., Wu, Y., Zhang, M., Zhu, H. \& Zou, M. H. (2014). Myeloperoxidase deletion prevents high-fat diet-induced obesity and insulin resistance. Diabetes, 63, 4172-4185.

Wensveen, F. M., Valentic, S., Sestan, M., Turk Wensveen, T. \& Polic, B. (2015). The "Big Bang" in obese fat: Events initiating obesity-induced adipose tissue inflammation. Eur J Immunol, 45, 2446-2456.

Xu, X. J., Apovian, C., Hess, D., Carmine, B., Saha, A. \& Ruderman, N. (2015). Improved Insulin Sensitivity 3 Months After RYGB Surgery Is Associated With Increased Subcutaneous Adipose Tissue AMPK Activity and Decreased Oxidative Stress. Diabetes, 64, 3155-3159.

Yeop Han, C., Kargi, A. Y., Omer, M., Chan, C. K., Wabitsch, M., O'Brien, K. D., Wight, T. N. \& Chait, A. (2010). Differential effect of saturated and unsaturated free fatty acids on the generation of monocyte adhesion and chemotactic factors by adipocytes: dissociation of adipocyte hypertrophy from inflammation. Diabetes, 59, 386-396.

Yuan, M., Konstantopoulos, N., Lee, J., Hansen, L., Li, Z. W., Karin, M. \& Shoelson, S. E. (2001). Reversal of obesity- and diet-induced insulin resistance with salicylates or targeted disruption of Ikkbeta. Science, 293, 1673-1677.

Zeeshan, H. M., Lee, G. H., Kim, H. R. \& Chae, H. J. (2016). Endoplasmic Reticulum Stress and Associated ROS. Int J Mol Sci, 17. 

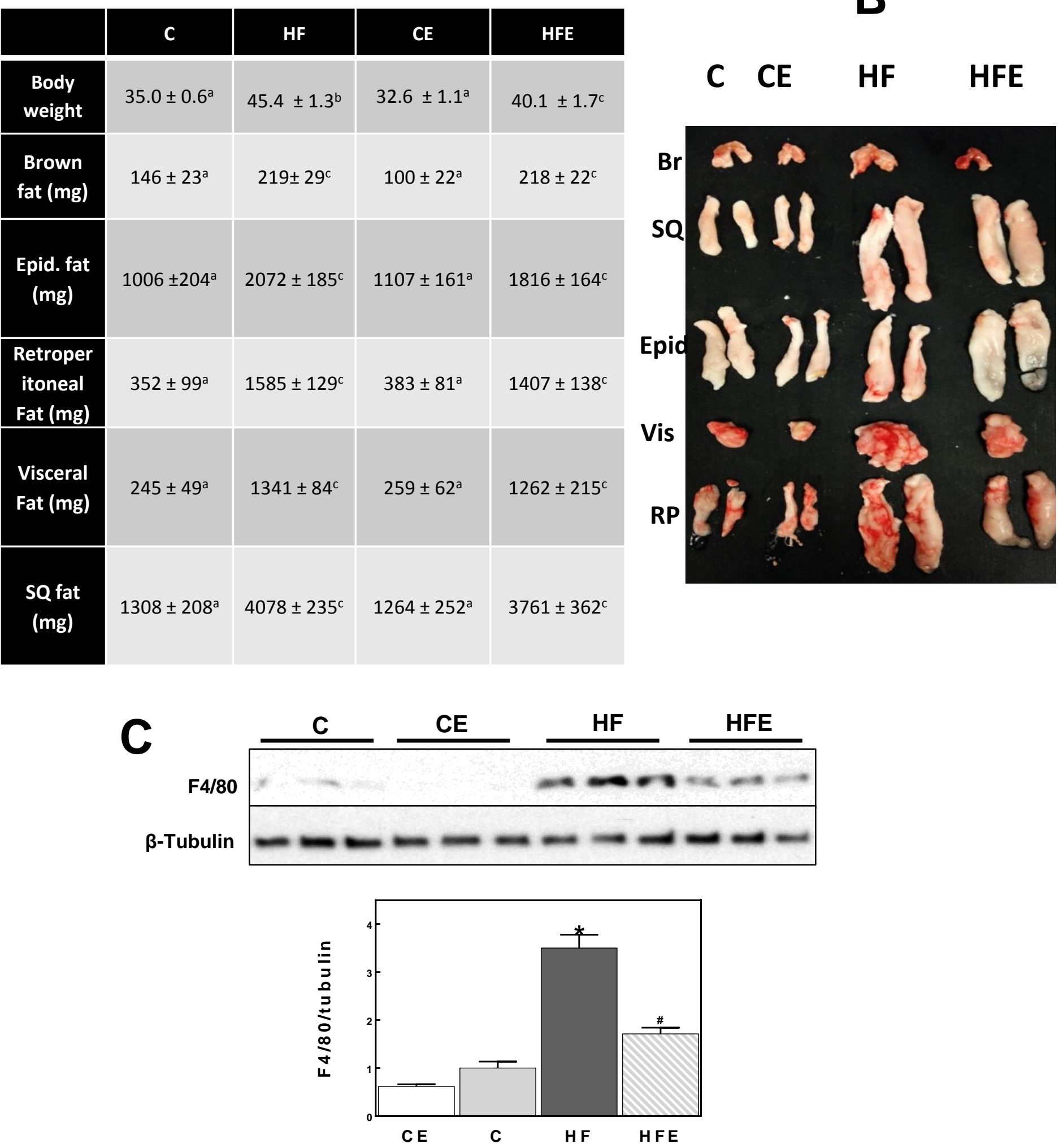

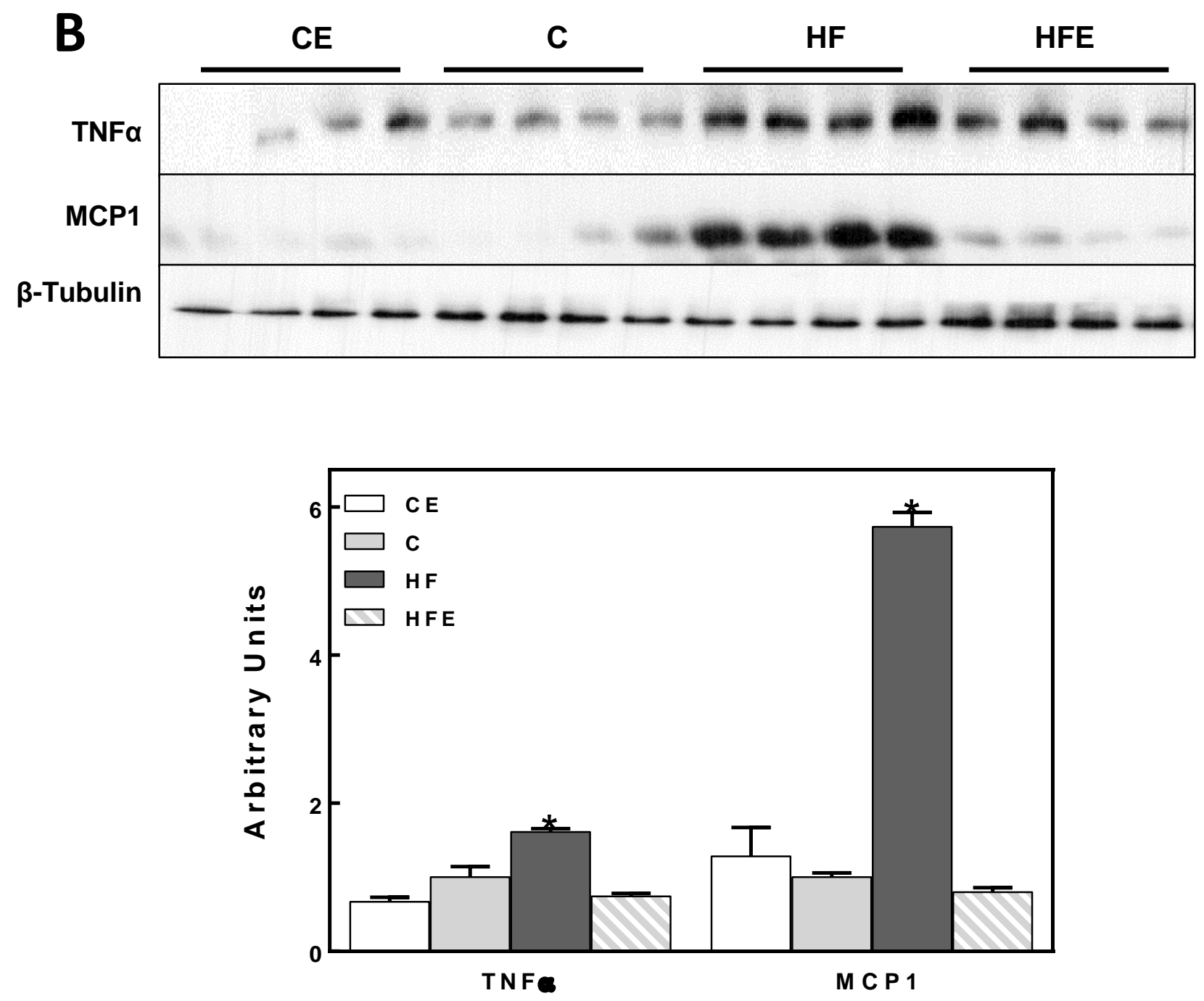

Figure 2 


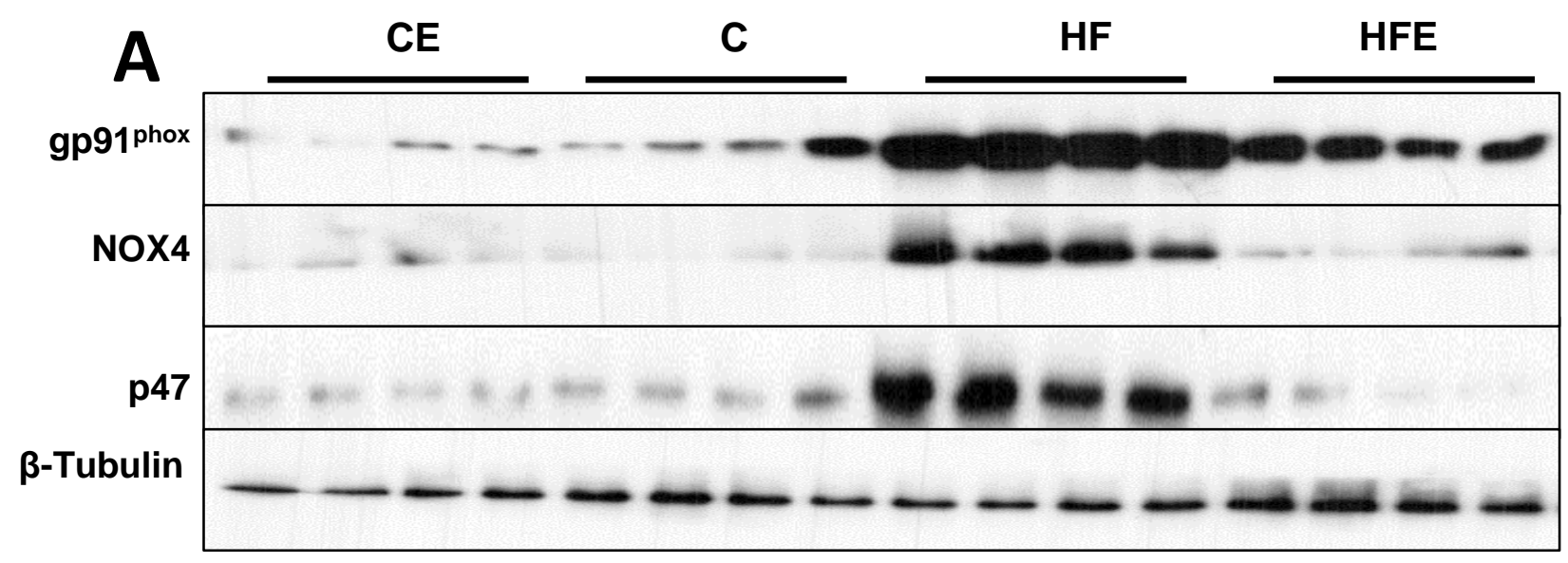

Figure 3
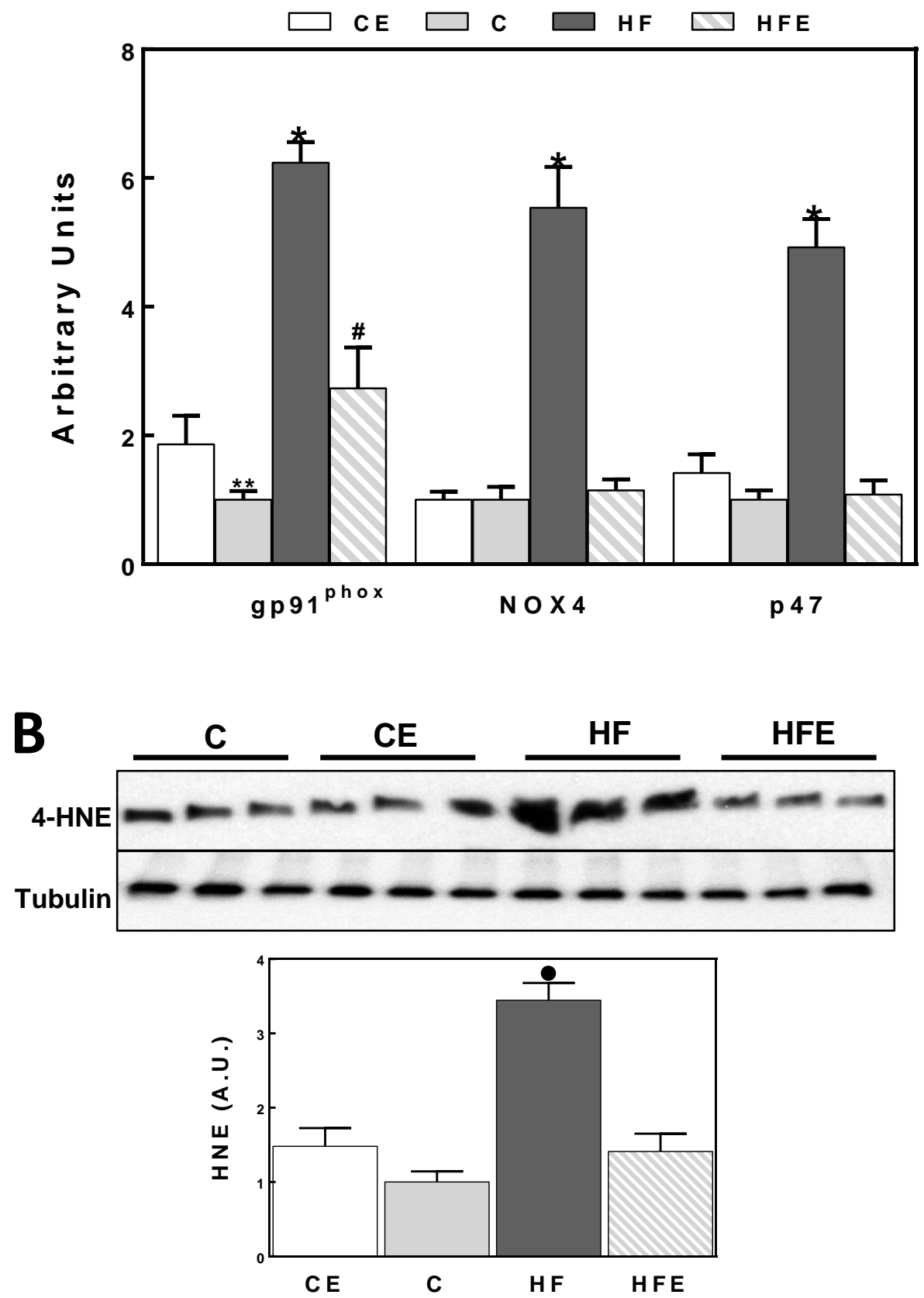

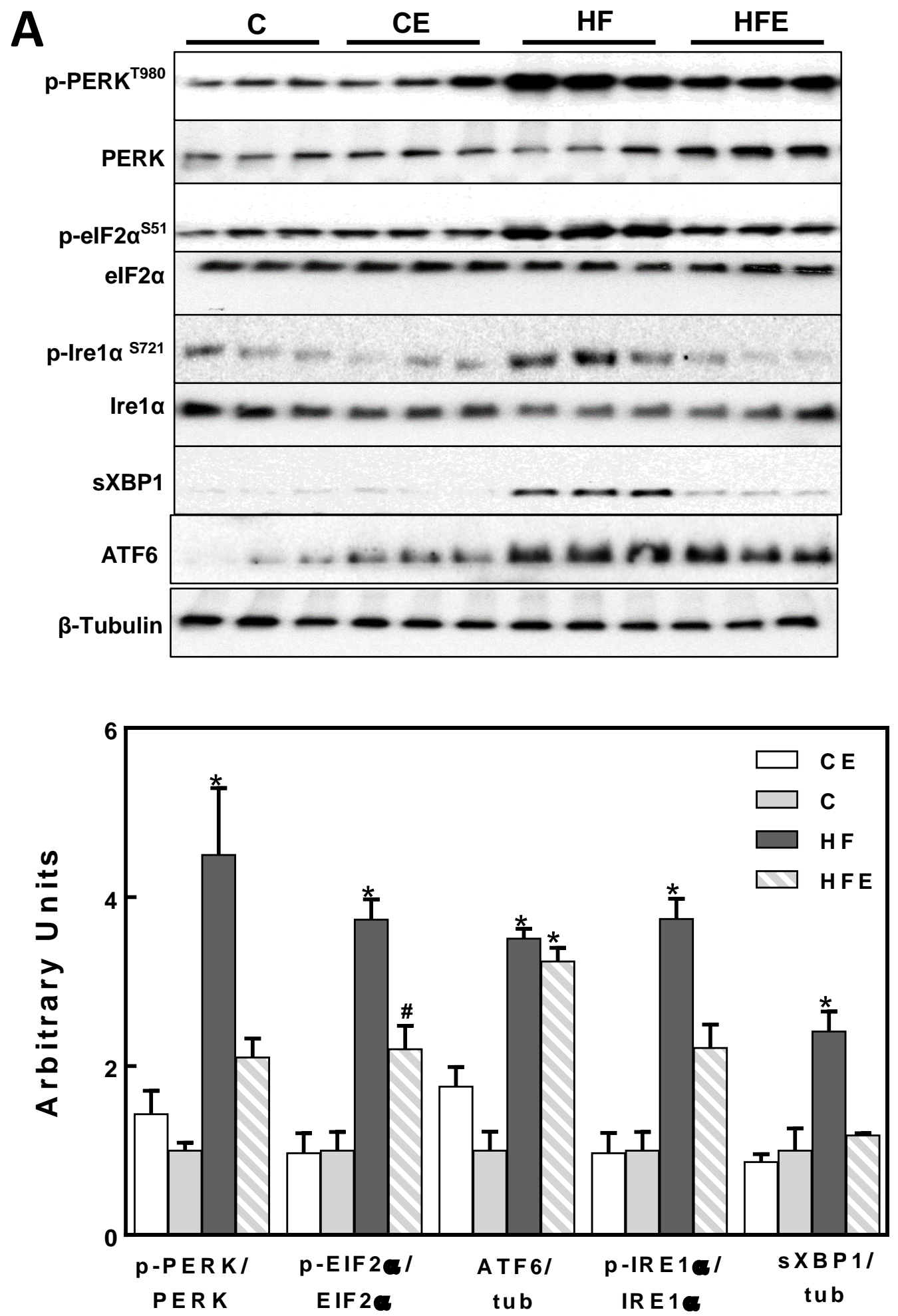

Figure 4 
B
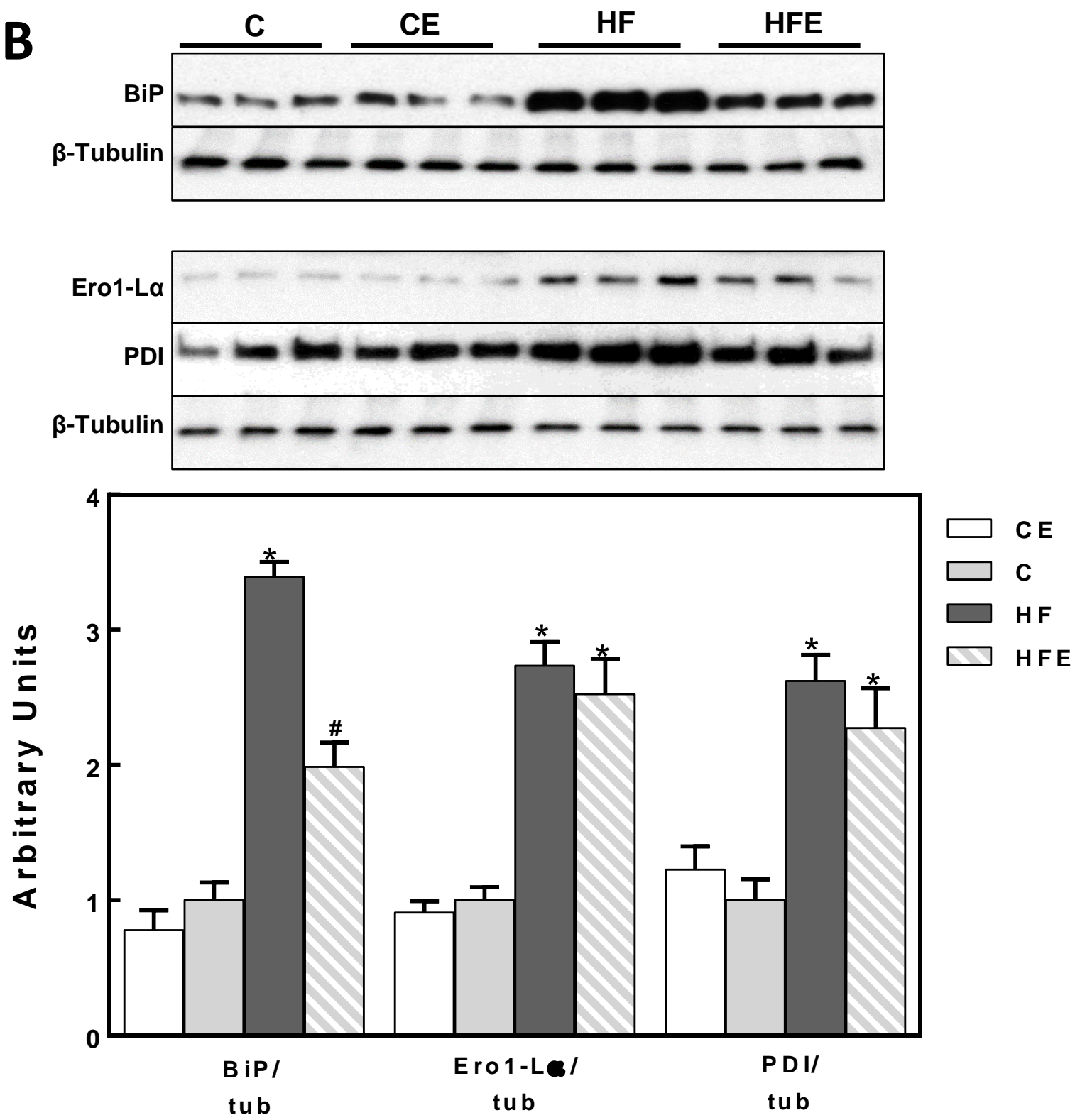

Figure 4 
A

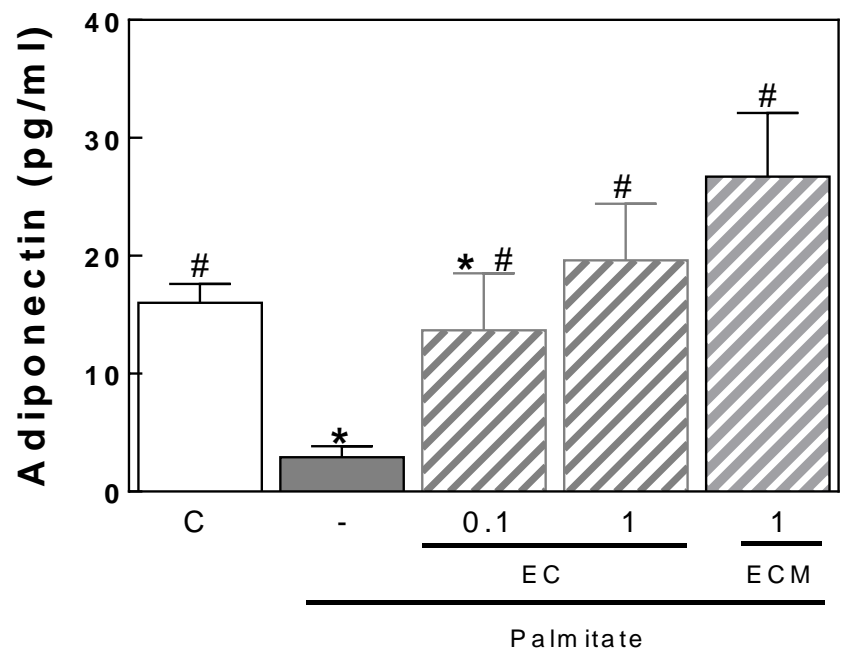

C

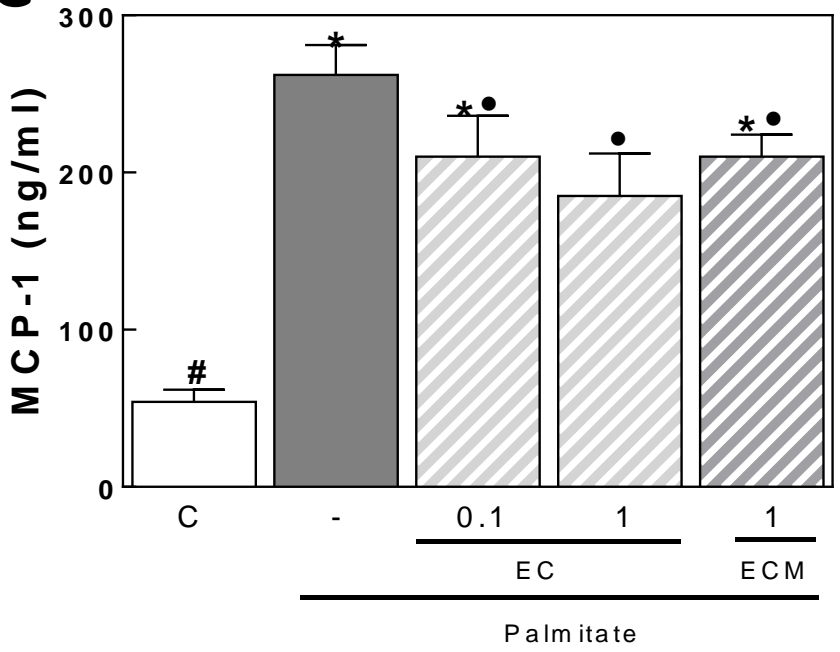

B

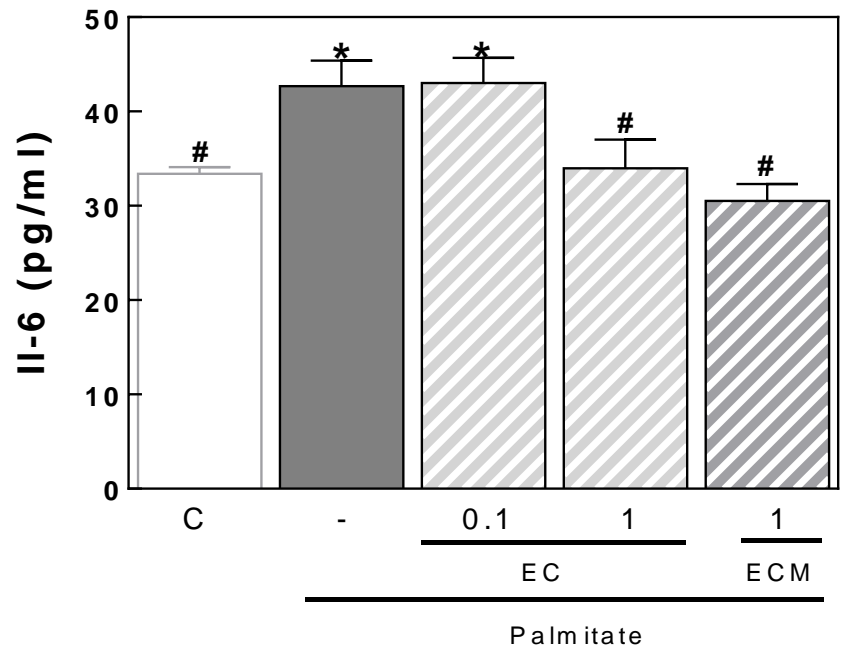

D

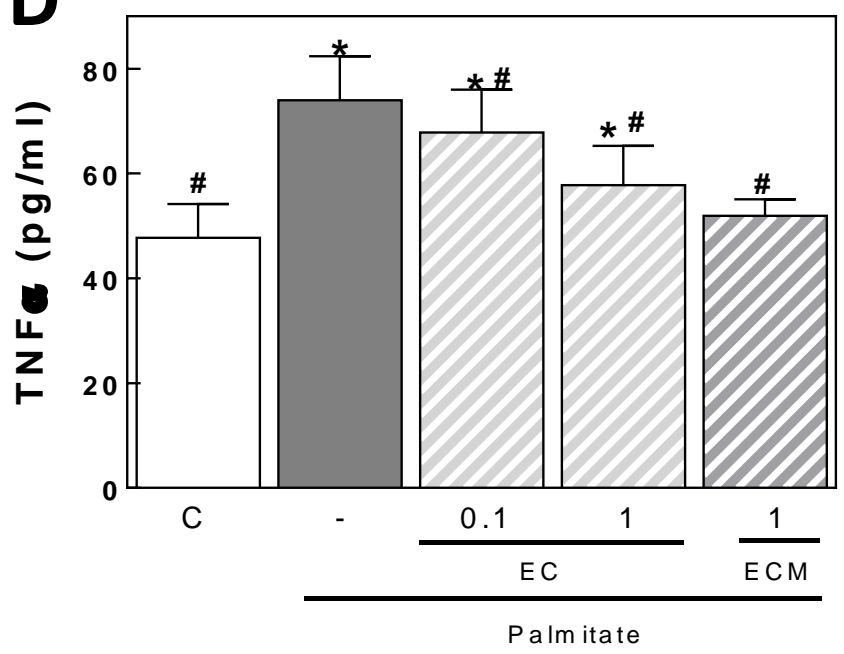




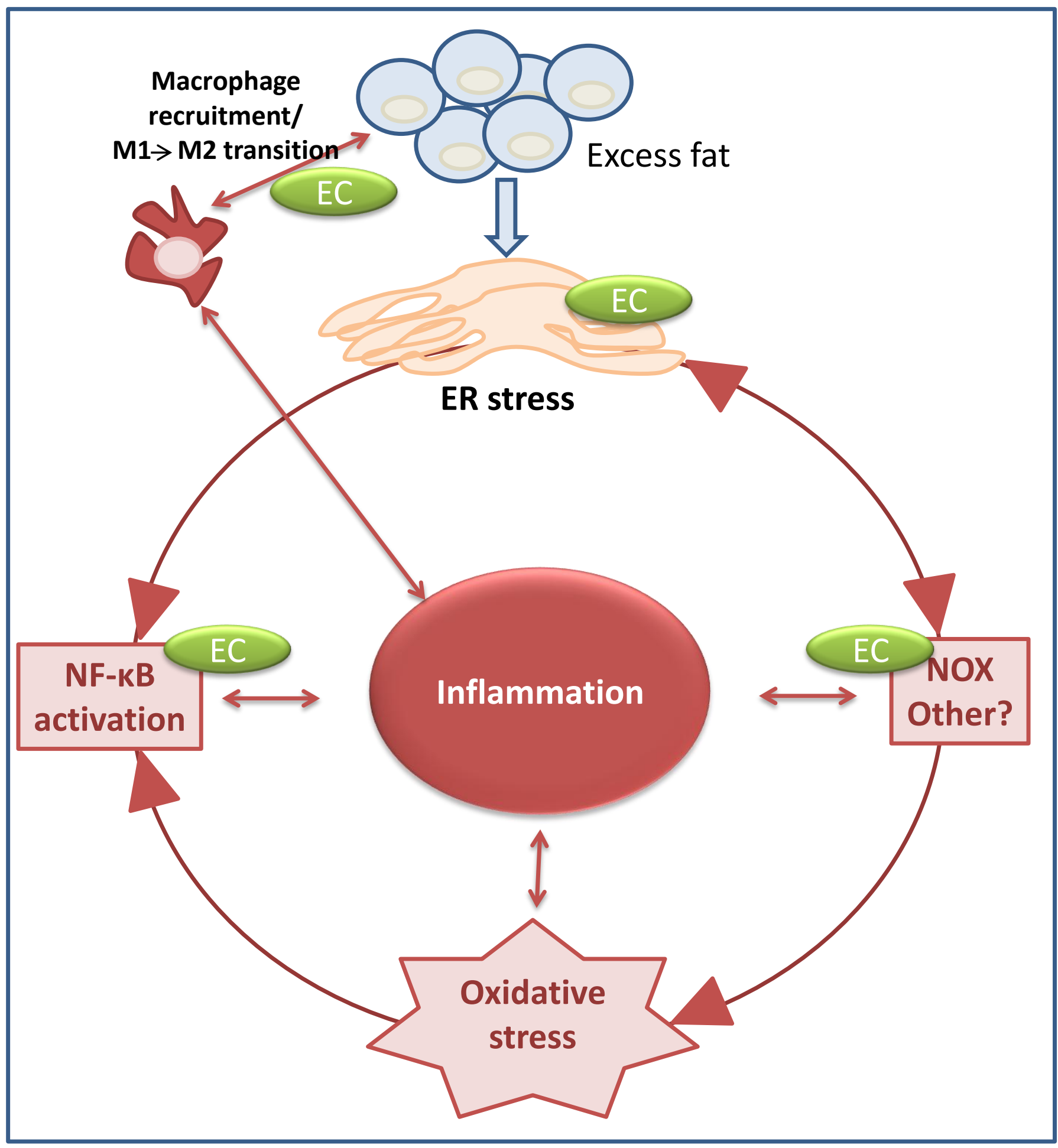

Figure 6 


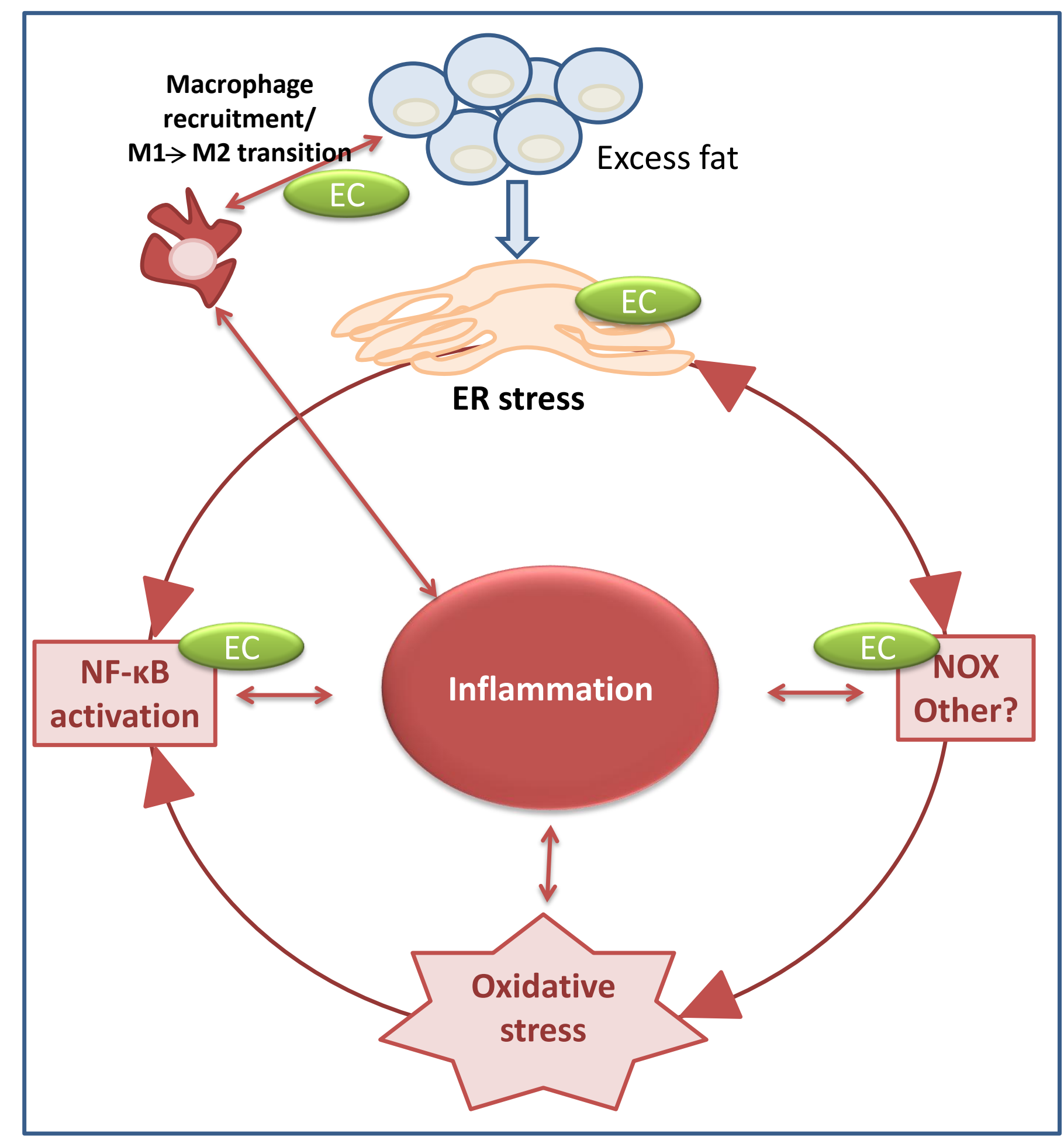

